\title{
Metabolic impact of the glycerol channels AQP7 and AQP9 in adipose tissue and liver
}

\author{
Janne Lebeck ${ }^{1,2}$ \\ ${ }^{1}$ The Danish Diabetes Academy, Odense, Denmark \\ ${ }^{2}$ Department of Biomedicine, Aarhus University, Wilhelm Meyers Allé 3, DK-8000 Aarhus, Denmark
}

Correspondence should be addressed to J Lebeck

Email

jl@ana.au.dk

\begin{abstract}
Obesity and secondary development of type 2 diabetes (T2D) are major health care problems throughout the developed world. Accumulating evidence suggest that glycerol metabolism contributes to the pathophysiology of obesity and T2D. Glycerol is a small molecule that serves as an important intermediate between carbohydrate and lipid metabolism. It is stored primarily in adipose tissue as the backbone of triglyceride (TG) and during states of metabolic stress, such as fasting and diabetes, it is released for metabolism in other tissues. In the liver, glycerol serves as a gluconeogenic precursor and it is used for the esterification of free fatty acid into TGs. Aquaporin 7 (AQP7) in adipose tissue and AQP9 in the liver are transmembrane proteins that belong to the subset of AQPs called aquaglyceroporins. AQP7 facilitates the efflux of glycerol from adipose tissue and AQP7 deficiency has been linked to TG accumulation in adipose tissue and adult onset obesity. On the other hand, AQP9 expressed in liver facilitates the hepatic uptake of glycerol and thereby the availability of glycerol for de novo synthesis of glucose and TG that both are involved in the pathophysiology of diabetes. The aim of this review was to summarize the current knowledge on the role of the two glycerol channels in controlling glycerol metabolism in adipose tissue and liver.
\end{abstract}
Key Words
- glycerol metabolism
- adipose tissue
- liver
- triglycerides
- obesity
type 2 diabetes

Journal of Molecular Endocrinology

(2014) 52, R165-R178

\section{Glycerol metabolism}

The metabolic switching between feeding and fasting is central to everyday life and involves tight hormonal control with effects on muscle, adipose tissue, and liver that maintains an adequate handling of metabolic precursors to support energy demands. One of the molecules affected by metabolic switching is glycerol, which is a small 3-carbon alcohol that in the fed state is stored as the backbone of triglyceride (TG) mainly in adipose tissue.

In the fed state, after ingestion of dietary fats ( 90\% TG), $<30 \%$ of TG is fully hydrolyzed into free fatty acids
(FFA) and glycerol. Glycerol rapidly enters the enterocytes of the small intestine and thereafter the circulation through the portal vein and is primarily metabolized by the liver (Lin 1977). In adipose tissue, the activity of glycerol kinase (GlyK), that catalyzes the initial phosphorylation of glycerol into glycerol-3-phosphate (G3P), is negligible and therefore glycerol is not normally utilized in adipose tissue. Instead G3P used for the synthesis of TG in the fed state is derived from glycolysis.

During states of increased energy demand, such as fasting and exercise, adipocyte lipolysis is increased by activation of adipose TG lipase and hormone-sensitive

Published by Bioscientifica Ltd. 
lipase, which initiates the breakdown of TG into FFA and monoacylglycerol (MAG), whereas the final step of converting MAG into FFA and glycerol is catalyzed by MAG lipase (Fig. 1). The major hormones involved in initiating lipolysis are low plasma levels of insulin, catecholamines acting through $\beta$-adrenergic receptors, and natriuretic peptides that in humans serve as potent stimulators of lipolysis (Lafontan \& Langin 2009, Kolditz \& Langin 2010). The generated FFA and glycerol are released to support energy demands in other tissues, and the efflux of glycerol from adipose tissue is facilitated by aquaporin 7 (AQP7). However, even in the fasted state, up to $65 \%$ of the generated FFA is re-esterified back into TG (Hanson \& Reshef 2003). A substantial part of the re-esterification occurs already within the adipocytes (Hammond \& Johnston 1987), and in contrast to the fed state, G3P is not derived from glucose, which is saved for metabolism by other tissues. Instead, the G3P used for re-synthesis of TG is primarily derived from glyceroneogenesis, which is a truncated form of gluconeogenesis that uses lactate, pyruvate, and alanine to generate G3P (reviewed in Hanson \& Reshef (2003) and Reshef et al. (2003); Fig. 1).

As mentioned earlier, the activity of GlyK in adipose tissue is very low under normal circumstances, and therefore, generated glycerol is exported to other tissues for further metabolism. Even though it is not supported by all studies (Tan et al. 2003), the activity of GlyK in adipocytes has been shown to be increased to significant levels in response to peroxisome proliferator-activated receptor $\gamma(\operatorname{PPAR} \gamma)$ activation. PPARs (PPAR $\alpha, \operatorname{PPAR} \beta / \delta$, and PPAR $\gamma$ ) are ligand-activated transcription factors that belong to the superfamily of nuclear hormone receptors. They are activated by the binding of ligands and regulate gene transcription by two pathways: i) heterodimerization with the retinoid $X$ receptor (RXR) and binding to PPAR response elements and ii) interfering with other transcription factor pathways in a DNA-independent manner (Yki-Jarvinen 2004). PPAR $\gamma$ agonists (thiazolidinediones) are used in the treatment of type 2 diabetes (T2D) due to their insulin-sensitizing effects (Guan et al. 2002, Leroyer et al. 2006). In addition to its effects on GlyK activity, the activation of PPAR $\gamma$ also increases glyceroneogenesis in adipose tissue (Tordjman et al. 2003, Leroyer et al. 2006) and the increased generation of G3P from both sources results in an increased FFA re-esterification that lowers the efflux of FFA from adipose tissue, which contributes to the insulin-sensitizing effects of PPAR $\gamma$ agonists (Guan et al. 2002, Leroyer et al. 2006).

The FFA released in response to increased energy demands is metabolized mainly in liver and skeletal

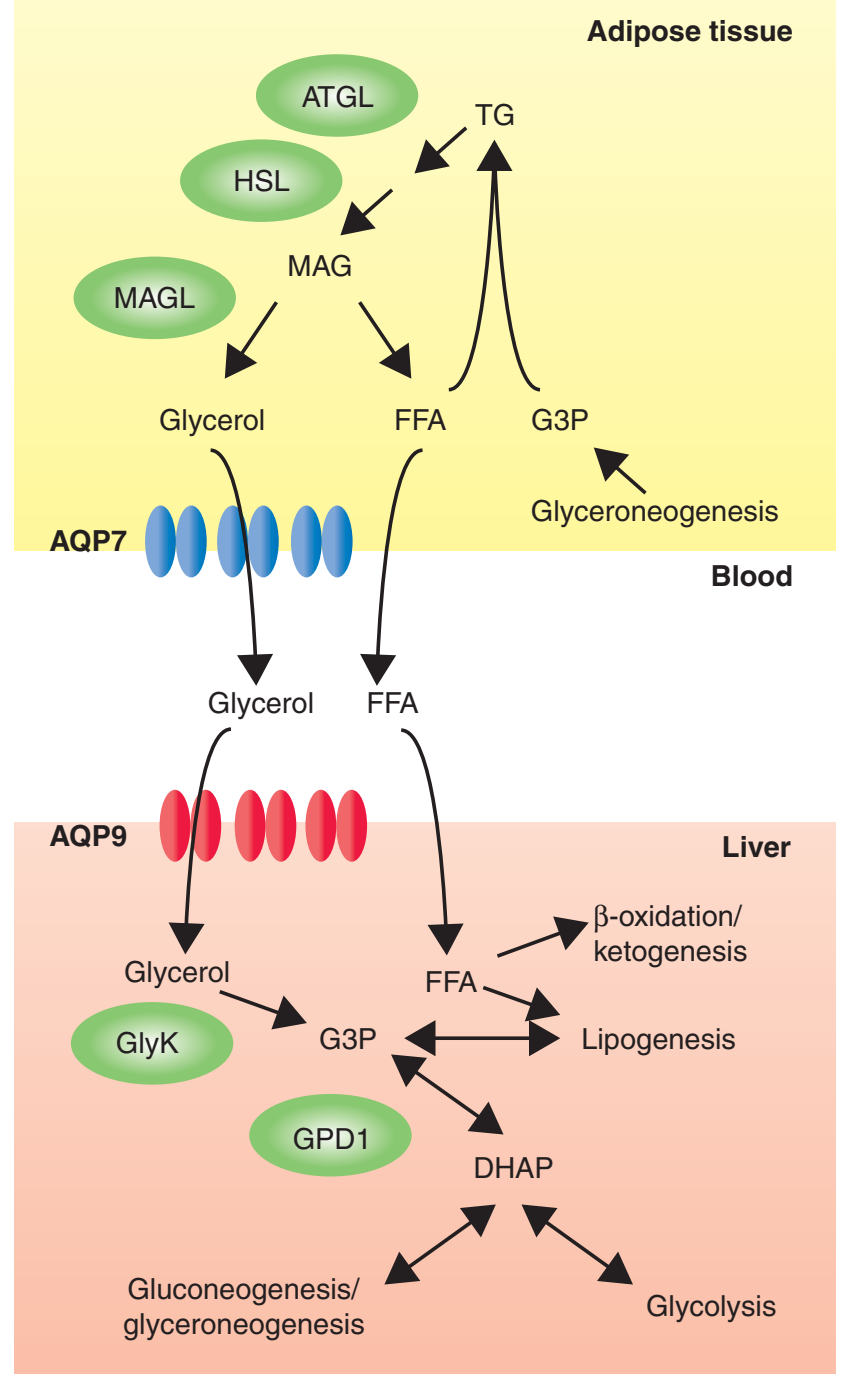

Figure 1

Cellular pathways involved in glycerol metabolism in adipose tissue and liver during fasting. In adipose tissue, triglyceride (TG) is hydrolyzed by adipose triglyceride lipase (ATGL) and hormone-sensitive lipase (HSL) into monoacylglycerol (MAG) that is hydrolyzed into free fatty acids (FFA) and glycerol by MAG lipase (MAGL). A substantial part of the generated FFA is re-esterified into TG. Glycerol-3-phosphate (G3P) used for lipogenesis during fasting is mainly derived from lactate, pyruvate, and alanine through a truncated form of gluconeogenesis called glyceroneogenesis. The release of generated glycerol from adipose tissue is facilitated by the glycerol channel aquaporin 7 (AQP7). Both glycerol and FFA then reaches the liver, where AQP9 facilitates the uptake of glycerol. Once inside the hepatocyte, glycerol is phosphorylated by glycerol kinase (GlyK) into G3P. During fasting, glycerol serves as a substrate for hepatic glucose de novo synthesis through gluconeogenesis and in order to enter that pathway G3P is oxidized by cytoplasmatic glycerol-3-phosphate dehydrogenase (GPD1) into dihydroxyacetone phosphate (DHAP). GPD1 also catalyzes the reverse reaction generating G3P from DHAP as the final step of glyceroneogenesis. During fasting, FFA is in the liver used for energy synthesis through $\beta$-oxidation and ketogenesis, and a substantial part of FFA is re-esterified into glycerolipids. The G3P used for lipogenesis during fasting is derived either from glycerol or glyceroneogenesis. 
muscle (Jensen 2003). In the fasted liver, FFA is used for $\beta$-oxidation and synthesis of ketone bodies, and also a substantial part of FFA is re-esterified into TG (Wolfe et al. 1990, Hellerstein et al. 1993, Baba et al. 1995). In the liver, AQP9 facilitates the uptake of glycerol and with the liver being one of the main expression sites for GlyK (Lin 1977), G3P for TG synthesis can here be derived from glycerol in addition to being generated from glyceroneogenesis and glycolysis. A substantial part of the generated G3P is used for gluconeogenesis. To enter this pathway, G3P is reversibly oxidized by cytoplasmatic glycerol-3phosphate dehydrogenase (GPD1) into dihydroxyacetone phosphate (Fig. 1). Measurements of how much glycerol ends up in TG synthesis vs gluconeogenesis have mainly been performed in humans. The results have been somewhat variable, with the reported proportion of glycerol used for TG synthesis ranging from only $\sim 6 \%$ in women after 16-h fasting (Kahn \& Flier 2000) to $>60 \%$ in young men fasted for $14 \mathrm{~h}$ (Baba et al. 1995). Similarly, measurement of the amount of glycerol used for gluconeogenesis in the fasted state also demonstrates great variability and ranges from $38 \%$ in lean men after a short fast to $\sim 100 \%$ in obese women after prolonged starvation (Bortz et al. 1972, Nurjhan et al. 1986, Baba et al. 1995, Landau et al. 1996). However, in general, the proportion of glycerol used for gluconeogenesis increases as the fasting period prolongs. Even though a large fraction of glycerol goes into glucose de novo synthesis, it still only makes a minor contribution to the hepatic generation of glucose after overnight fasting but becomes increasingly important as a gluconeogenic precursor with prolonged fasting. Thus, the amount of de novo synthesized glucose ascribed to glycerol was 4.5 and $21.6 \%$ respectively in healthy men fasted for 14 and $62-86 \mathrm{~h}$ (Baba et al. 1995). In rats, glycerol has been found to account for $\sim 25 \%$ of the glucose derived from gluconeogenesis after both 6 and $48 \mathrm{~h}$ of fasting (Peroni et al. 1997).

\section{AQP protein family}

The AQPs are pore-forming transmembrane proteins that share a variable part of their amino acid sequences and have two highly conserved asparagine-proline-alanine (NPA) motifs, one in each half of the protein. They share the same basic architecture with a cytosolic N- and C-terminus and a hydrophobic stretch of six transmembrane domains, connected by three extracellular and two intracellular loops. The transmembrane domains form an hourglass structure with the NPA motifs at the center of the molecule (reviewed in Magni et al. (2006)). Several observations of
AQP monomers forming a homotetrameric organization in the membrane have been made (Engel et al. 2000), and this feature is probably similar for all members of the AQP family. Transport through AQPs is not an active process and is dependent on the presence of a gradient across the membrane in question (Pastor-Soler et al. 2001).

At this time, 13 mammalian AQPs (AQPO-12) have been identified and the AQP family has been divided into three subgroups based on both their permeability characteristics and their amino acid sequence homology. The first group is the classical AQPs that are selective water channels. The second group is the aquaglyceroporins, which are capable of transporting glycerol and other small uncharged solutes in addition to water. Both AQP7 and AQP9 belong to this group together with AQP3 and AQP10. Atomic resolution analysis shows that GlpF, the aquaglyceroporin prototype in Escherichia coli, has a wider pore in the hourglass-like structure compared with the water-selective AQPs allowing the pore to accept larger molecules such as glycerol (Weissenborn et al. 1992). Finally, the third group is the unorthodox AQPs. As outlined above, AQP7 and AQP9 have emerged as important facilitators of glycerol transport across the cell membrane in adipose tissue and liver respectively and the focus of the present review will be the role of AQP7 in adipose tissue and AQP9 in liver in controlling the cellular availability and metabolism of glycerol.

\section{Aquaporin 7}

\section{Structure and permeability profile}

The AQP7 gene was first cloned from rat testis and encodes a protein of 269 amino acids with a predicted molecular mass of $28.9 \mathrm{kDa}$. The deduced amino acid sequences of human AQP7 and mouse AQP7 are 68 and 79\% identical to the rat $\mathrm{AQP7}$ respectively, and mouse AQP7 is 67\% identical to human AQP7. Thus, in contrast to other AQPs, AQP7 demonstrates an unusual low conservation among species (Kondo et al. 2002). Hydropathy analysis predicts six putative transmembrane domains with the $\mathrm{N}$ - and C-terminal localized in the cytosol. No potential $\mathrm{N}$-linked glycosylation sites or PKA phosphorylation sites have been identified in the predicted amino acid sequence; however, a potential PKC phosphorylation site has been found at residue Thr-174 (Ishibashi et al. 1997). In rat AQP7, the first NPA motif is present but the second NPA motif is NPS (asparagine-proline-serine) (Ishibashi et al. 1997). In human AQP7, it is the first NAA (asparagine-alanine-alanine) motif that is substituted by NAA, whereas the second NPA

Published by Bioscientifica Ltd 
motif is preserved (Kuriyama et al. 1997). AQP7 shows permeability to water, glycerol, and urea when expressed in Xenopus oocytes, (Kuriyama et al. 1997, Ishibashi et al. 1997, Kishida et al. 2001a).

\section{Localization of AQP7 in adipose tissue}

An important part of establishing the function of a protein is to identify its cellular and subcellular localization within a given tissue. AQP7 has been localized to a wide range of different tissues in both rodents and humans. Here, we restrict our focus to AQP7 expressed in adipose tissue and only comment on the localization or function in other tissues when this could influence the interpretation of the role of AQP7 in adipose tissue glycerol metabolism. Hence, AQP7 expressed in kidney, pancreas, and muscle will also be mentioned below. The overall localization profile of AQP7 has been thoroughly revised by Rojek et al. (2008).

Controversy still exists on the cellular and subcellular localization of AQP7 in adipose tissue. The hypothesis on AQP7 as a facilitator of glycerol transport in adipose tissue has been founded on the assumption that AQP7 is expressed in the adipocyte plasma membrane (Fruhbeck 2005, Fruhbeck et al. 2006, Maeda et al. 2008, 2009). Supporting a localization in adipocytes, AQP7 mRNA and protein is detected in adipocyte cell culture models such as differentiated 3T3-L1 (mouse embryonic fibroblasts - adipose-like cell line; Kishida et al. 2000, 2001a,b) and SGBS cells (human preadipocyte cell strain; Miranda et al. 2010). Furthermore, fractionation of human adipose tissue into adipocytes and stromovascular fraction cells resulted in the highest abundance of $A Q P 7$ mRNA and protein in the adipocyte containing fraction (Miranda et al. 2010). Immunostaining for AQP7 in adipocyte cell culture models demonstrates a predominant localization in intracellular regions (Kishida et al. 2000, Miranda et al. 2010, Rodriguez et al. 2011), which does not apply to a role in transporting glycerol across the plasma membrane. Stimulation of the cells with epinephrine/isoproterenol have been reported to result in translocation of some of the AQP7 labeling to the plasma membrane domain (Kishida et al. 2000, Rodriguez et al. 2011, Laforenza et al. 2013), in turn suggesting that AQP7 traffics to the plasma membrane in response to lipolytic stimuli.

The above outlined observations are somewhat contrasted by the results obtained by immunohistochemical analysis of AQP7 expression in adipose tissue. Using paraffin sections from mouse and human adipose tissue, we have been unable to detect labeling for AQP7 in the adipocytes; instead strong labeling for AQP7 is found in the capillary endothelial cells (Skowronski et al. 2007,
Lebeck et al. 2012a). Furthermore, in transgenic mice with eGFP expression driven by the AQP7 promoter, the expression of eGFP was also only found in the endothelial cells of the small capillaries within the adipose tissue (Lebeck et al. 2012a). The localization of AQP7 to the endothelial cells within human adipose tissue has been confirmed by others (Rodriguez et al. 2011, Laforenza et al. 2013). However, in their studies, they also detected labeling for AQP7 in the adipocytes. This discrepancy could be explained by differences in fixation methods or the specificity of the antibodies used. The unilocular nature of the adipocytes in white adipose tissue (WAT), with only a thin peripheral rim of cytoplasm, makes it difficult to interpret the subcellular localization of staining for AQP7 in adipocytes. Therefore, provided that AQP7 is also present in the adipocytes, studies using electron microscopy are needed to clarify whether trafficking of AQP7 from intracellular domains to the plasma membrane occurs in vivo. Thus, further studies are needed to sediment the cellular and subcellular localization of AQP7 in adipose tissue. However, whether AQP7 is found in endothelial cells alone or in both adipocytes and endothelial cells, it will either way play a role in facilitating glycerol transport between the adipocyte and the blood and thereby be able to influence glycerol metabolism.

\section{Is AQP7 the sole aquaglyceroporin in adipose tissue?}

The putative presence of other aquaglyceroporins in adipose tissue has been investigated with variable outcomes. Neither Aqp3 nor Aqp9 mRNA are detected by northern blotting of white or brown adipose tissue from mice (Kishida et al. 2000, Maeda et al. 2004), and although not supported by all studies (Rodriguez et al. 2011), similar results have been obtained for human WAT (Miranda et al. 2010, Lebeck et al. 2012a). A recent study suggests the presence of AQP10 in human WAT with localization only to the adipocytes (Laforenza et al. 2005). However, again this observation is disputed by others having been unable to detect AQP1O mRNA in adipose tissue (Miranda et al. 2010). Thus, the cellular expression of aquaglyceroporins in adipose tissue needs clarification in order to validate their potential role and possible overlap in facilitating glycerol transport within adipose tissue.

\section{Regulation of AQP7 expression in adipose tissue}

In adipose tissue, the abundance of $A Q P 7$ mRNA and protein is inversely regulated by insulin, with increased expression during fasting and decreased expression during

Published by Bioscientifica Ltd. 
refeeding (Kishida et al. 2001a). Increased abundance of AQP7 mRNA (Kishida et al. 2001a) and protein (Skowronski et al. 2007) has also been found in response to streptozotocin (STZ)-induced diabetes mellitus as well as in insulin resistant $\mathrm{db}+/ \mathrm{db}+$ mice (Kuriyama et al. 2002). These conditions are associated with an increased hydrolysis of TG into glycerol and FFA and release of these into the bloodstream, which agrees with AQP7 facilitating glycerol transport. A functional negative insulin response element (IRE) has been identified in the promoter region of the $A Q P 7$ gene from both humans ( -542 to $-536 \mathrm{bp}$ upstream of the translation initiation site) (Kondo et al. 2002) and mice ( -443 to $-437 \mathrm{bp}$ ) (Kishida et al. 2001a). The suppression of AQP7 transcription was abolished when an inhibitor of the PI3K pathway was administered, indicating that this pathway mediates the suppression of AQP7 expression by insulin (Kishida et al. 2001a).

In addition to the IRE, a peroxisome proliferator response element (PPRE) has also been identified in the promoter region of both the mouse ( -93 to $-77 \mathrm{bp}$ ) and human ( -62 to -46 bp) AQP7 gene (Kishida et al. 2001b, Kondo et al. 2002). Analysis of the mouse PPRE demonstrated that $A Q P 7$ is a PPAR $\gamma$ target gene and binding of $\operatorname{PPAR} \gamma$ after heterodimerization with the RXR $\alpha$ caused an increased Aqp7 mRNA expression in 3T3-L1 adipocytes. As well as treatment of mouse and rats with PPAR $\gamma$ agonists increased the expression of AQP7 in adipose tissue (Kishida et al. 2001b, Lee et al. 2005). As mentioned earlier, PPAR $\gamma$ agonists have insulin-sensitizing effects and in addition to their effects on AQP7 in adipose tissue, they stimulate the generation of G3P and an increased availability of FFA subsequently resulting in an increased storage of TG (Lehrke \& Lazar 2005). It does, however, seem contradictive that when AQP7 is already increased in insulin-resistant $\mathrm{db}+/ \mathrm{db}+$ mice (Kuriyama et al. 2002), then a further increase due to stimulation by PPAR $\gamma$ agonists would be a means of improving insulin sensitivity. A possible explanation could be that a parallel increase in GlyK activity results in a shift in the gradient for glycerol flux and thus promotes the use of glycerol for TG synthesis in response to PPAR $\gamma$-agonist treatment, whereas the increased AQP7 expression in $\mathrm{db}+/ \mathrm{db}+$ mice facilitates an increased efflux of the glycerol generated from hydrolysis of TG.

Similar to the results obtained for PPAR $\gamma$, activation of both PPAR $\beta / \delta$ (Patsouris et al. 2004) and PPAR $\alpha$ (Walker et al. 2007) have been reported to increase the abundance of $A Q P 7$ mRNA in adipocyte cell culture models. Finally, the effect of other hormones has been investigated in differentiated 3T3-L1 cells, and it has been shown that isoproterenol, tumor necrosis factor $\alpha$, and dexamethazone decreases the expression of $A Q P 7 \mathrm{mRNA}$, while angiotensin 2 , growth hormone, triiodothyronine, epinephrine, glucagon, and adrenocorticotropic hormone had no effect on the abundance of $A Q P 7$ mRNA (Kishida et al. 2000, Fasshauer et al. 2003). The apparently diverging results obtained for isoproterenol and epinephrine could be due to differences in selectivity, with isoproterenol being a selective $\beta$-agonist. However, in differentiated 3T3-L1 adipocytes, the relative higher abundance of the $\beta_{3^{-}}$vs $\alpha_{2}$-adrenergic receptors (El Hadri et al. 1996, Monjo et al. 2005) predicts that the effect of epinephrine should also mainly be due to activation of $\beta$-adrenergic receptors and thus does not seem to explain the discrepancy. Furthermore, as outlined above, both isoproterenol and epinephrine have been reported to induce trafficking of AQP7 to the plasma membrane in in vitro systems. Should this trafficking also occur in vivo, then the effect on the total abundance of AQP7 protein in the plasma membrane needs to be determined.

\section{Effects of AQP7 deficiency on glycerol metabolism}

The metabolic impact of AQP7 in adipose tissue has been highlighted by the interesting phenotype observed in two different lines of AQP7 knockout (KO) mice (Maeda et al. 2004, Hara-Chikuma et al. 2005, Hibuse et al. 2005). The lack of AQP7 in both cases resulted in an increased accumulation of glycerol and TG within the adipocytes leading to adipocyte hypertrophy (Hara-Chikuma et al. 2005, Hibuse et al. 2005). The first AQP7 KO line had lower p-glycerol levels together with similar p-FFA levels in both the fed and fasted state compared with WT littermates. Furthermore, the young KO mice responded to fasting with lower p-glucose levels, suggesting an impaired de novo synthesis of glucose and no differences in p-insulin levels were observed (Maeda et al. 2004). When followed past the age of 12 weeks, these male AQP7 KO mice developed adult-onset obesity with adipocyte hypertrophy, and at 20 weeks of age, the $\mathrm{KO}$ mice responded to fasting with higher p-glucose, p-insulin, p-leptin, and p-FFA levels than WT littermates, whereas p-glycerol remained lower in the $\mathrm{KO}$ mice. The aged AQP7 KO mice demonstrated wholebody insulin resistance. The proposed mechanism behind the adipocyte hypertrophy is that an increased accumulation of glycerol within the adipocytes increases the activity of GlyK and, thus, results in an increased synthesis of TG within the adipose tissue (Fig. 2) which leads to obesity and secondary development of insulin resistance (Hibuse et al. 2005).

Published by Bioscientifica Ltd. 


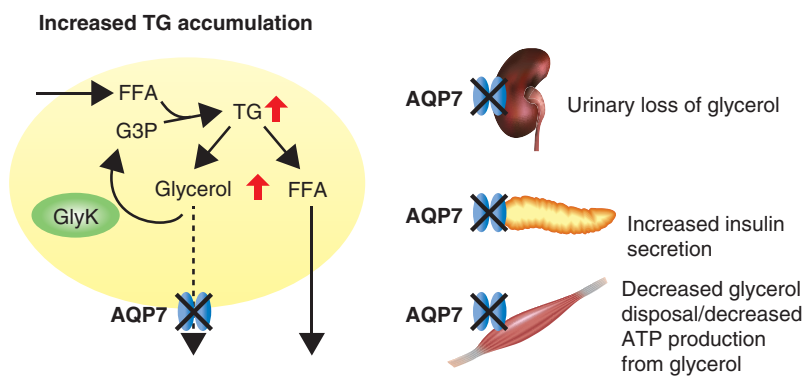

Figure 2

Tissues potentially contributing to the overall metabolic phenotype of AQP7 knockout mice. In adipose tissue, the lack of AQP7 is hypothesized to result in an increased accumulation of glycerol, which in turn stimulates the activity of glycerol kinase (GlyK). This leads to increased synthesis of glycerol-3-phosphate (G3P) and triglyceride (TG). The accumulation of TG eventually results in adipocyte hypertrophy and adiposity. In the kidney, lack of AQP7 in the proximal tubule brush border results in marked urinary loss of glycerol. In pancreatic $\beta$-cells, lack of AQP7 results in accumulation of glycerol and TG by a mechanism similar to that described for adipose tissue. This is associated with an increased secretion of insulin and, thus, increased plasma insulin levels, without changes in peripheral insulin sensitivity. Finally, in cardiac muscle, and potentially also in skeletal muscle, the lack of AQP7 results in a decreased uptake of glycerol and thereby a decreased generation of energy from glycerol.

In the second line of AQP7 KO mice, the agedependent increase in fat mass with increased glycerol and TG content was confirmed (Hara-Chikuma et al. 2005). However, these KO mice had a similar weight gain as WT animals but had a reduced body length. Also no differences were found in serum levels of glycerol, FFA, and TG between $\mathrm{KO}$ and WT female mice, and the rate of lipolysis and lipogenesis in WAT seemed unaffected.

This intriguing phenotype suggests that lowering of adipocyte AQP7 expression or function is associated with an increased susceptibility for the development of obesity and insulin resistance. On the other hand, the studies performed in insulin-resistant $\mathrm{db}+/ \mathrm{db}+$ mice demonstrated an increased expression of $\mathrm{AQP7}$ in adipose tissue. Therefore, when investigating the expression of AQP7 in obese and insulin-resistant individuals, diverging results could be due to whether AQP7 is part of the development or the consequence of insulin resistance.

Nonetheless, it should be noted that two additional AQP7 KO mouse lines have been generated that do not support the findings presented above. In both these lines, no effect on body weight or fat pad masses were detected, and neither were there any differences between $\mathrm{KO}$ and WT animals in the plasma levels of glycerol, FFA, or TGs (Matsumura et al. 2007, Skowronski et al. 2007). Possible reasons for these variations could be due to different gene targeting strategies, different genetic backgrounds, or differences in collection and analysis of tissue samples.

Another important point to include when investigating the phenotype of AQP7 KO animals is the expression of AQP7 in other tissues with relevance for development of obesity and T2D as outlined in Fig. 2. In the kidney, AQP7 is localized to the apical plasma membrane of the proximal convoluted tubule (Ishibashi et al. 2000, Nejsum et al. 2000, Skowronski et al. 2007, Lebeck et al. 2012a). Investigations in AQP7 KO mice found that AQP7 only plays a minor role in water permeability of the proximal tubule (Sohara et al. 2005), whereas it plays a major role in urinary glycerol reabsorption. These mice display a marked urinary loss of glycerol and, thus, loss of energy, which per se would not predict susceptibility to development of obesity (Sohara et al. 2005, Skowronski et al. 2007). Like the lower efflux of glycerol from adipose tissue, then the urinary loss of glycerol would predict a reduction in p-glycerol levels in AQP7-deficient mice. AQP7 is also found in skeletal and cardiac muscle (Skowronski et al. 2007), and at least in cardiac muscle AQP7 is reported to play a significant role in supplying glycerol for energy production within the myocytes (Hibuse et al. 2009). The lack of AQP7 would here predict a reduced glycerol disposal that would increase the plasma glycerol levels. In parallel, it would also increase the need for other precursors than glycerol to support energy needs within muscle tissue. Finally, AQP7 has also been localized to pancreatic $\beta$-cells (Matsumura et al. 2007, Best et al. 2009). Despite the apparent intracellular localization of $\mathrm{AQP7}$, the AQP7 KO mice were reported to have a higher intra-islet glycerol and TG content with an increased activity of GlyK similar to that observed in WAT from the first KO line. This was accompanied by an increased secretion of insulin, increased p-insulin levels with no effect on p-glucose, and with no evidence of insulin resistance (Matsumura et al. 2007). Owing to the wide expression profile of $\mathrm{AQP7}$, the relative contribution of the different tissues to the phenotype of the total AQP7 KO mouse model seems difficult to define. Hence, there seems to be several candidate tissues affecting glycerol metabolism in parallel as well as the stated effect on pancreatic $\beta$-cells will influence energy metabolism at a more general level. In future studies, tissue-specific AQP7 KO mice would be a means to overcome this problem.

\section{Human studies on the role of AQP7 in obesity and T2D}

After the linkage between deficient AQP7 expression in adipose tissue and obesity with development of insulin resistance was proposed, several human studies have been

Published by Bioscientifica Ltd 
undertaken to investigate whether dysregulation of adipose tissue AQP7 expression is involved in the pathophysiology of obesity and T2D in humans. In support of human relevance, the human $A Q P 7$ gene is localized in a chromosomal region with reported linkage to T2D (Luo et al. 2001, Lindgren et al. 2002) and the metabolic syndrome (Loos et al. 2003).

An association study performed in Caucasian men and women has shown a connection between obesity and secondary development of $\mathrm{T} 2 \mathrm{D}$ and a common single nucleotide polymorphism (SNP) (A-953G) in the promoter of AQP7. The SNP causes decreased transcriptional activity by impairing $\mathrm{C} / \mathrm{EBP} \beta$ binding to the promoter region and was coupled to decreased $A Q P 7$ mRNA abundance in adipose tissue. Interestingly, this association was only observed among the female participants (Prudente et al. 2007). Thus, the role of AQP7 in human adipose tissue metabolism seems to be influenced by gender, and it indicates that in women a high AQP7 expression level in adipose tissue is desirable. This assumption is supported by the higher abundance of AQP7 in WAT found in women compared with men (Sjoholm et al. 2005, Lebeck et al. $2012 a$ ). Along the same line, we investigated the effect of a 10-week exercise program on AQP7 protein expression in abdominal subcutaneous adipose tissue (SAT) from healthy non-obese men and women and found that women responded by increasing the abundance of AQP7 protein, whereas in men, a reduced expression of AQP7 in SAT was observed (Lebeck et al. 2012a). Whether a similar gender-specific response to exercise also applies to visceral adipose tissue (VAT) remains to be investigated. However, the higher need for AQP7 to support glycerol efflux from adipose tissue in women seems well related to the higher plasma glycerol level found in women in response to metabolic stress such as fasting (Hales et al. 1965, Clore et al. 1989, Mittendorfer et al. 2001) and exercise (Davis et al. 2000, Galassetti et al. 2002, Mittendorfer et al. 2002).

The influence of gender might explain why an apparent metabolic phenotype was absent from a male subject homozygous for a loss-of-function mutation in the sixth transmembrane domain of AQP7 (G264V). A lack of increase in p-glycerol was observed in the G264V individual only when stressed by exercise (Kondo et al. 2002). Another group analyzed a mixed gender cohort of 178 Caucasians and found no association between the G264V mutation and either obesity or T2D. However, only one subject was homozygous for the mutation and that individual was obese, with T2D and p-glycerol levels below the 10th percentile (Ceperuelo-Mallafre et al. 2007). Recently, homozygosity for the G264V mutation in AQP7 was reported in three unrelated children with psychomotor retardation, hyperglyceroluria, normoglycerolemia, and a mild platelet secretion defect. No apparent metabolic phenotype was observed in either the three affected children or their normal homozygous siblings or heterozygous parents (Goubau et al. 2013).

Other human studies have evaluated the relative AQP7 abundance in adipose tissue from obese and T2D subjects with conflicting results. Several studies have found a reduced $A Q P 7$ mRNA expression in SAT from obese men and women (Marrades et al. 2006, CeperueloMallafre et al. 2007, Rodriguez et al. 2011). However, one study reported unchanged $A Q P 7$ mRNA abundance in SAT, whereas in VAT increased $A Q P 7$ gene expression was observed when comparing obese with overweight individuals from a mixed gender cohort (Miranda et al. 2010). Most of the studies evaluating the $A Q P 7$ mRNA expression in association with T2D did not find significant changes in the expression in SAT or VAT (Ceperuelo-Mallafre et al. 2007, Catalan et al. 2008, Miranda et al. 2009, 2010, Lebeck et al. 2012a), but an increased AQP7 abundance in VAT (Miranda et al. 2010, Rodriguez et al. 2011) has also been reported. These studies were performed in mixed gender cohorts, except for two studies (Catalan et al. 2008, Lebeck et al. 2012a).

In summary, the human data does point toward an association between a reduced expression of AQP7 and obesity, at least in women. The link to T2D, if any, seems to be secondary to obesity. Like the studies in the KO mice, no clear correlation between plasma glycerol and adipose tissue AQP7 expression was observed in the human studies. In order to further evaluate this, more studies with a focus on AQP7 expression in states prior to development of obesity or type diabetes are needed. Ideally, this would include a follow-up at a later time point, as the studies performed in obese or diabetics cannot provide much clarification as to whether a changed AQP7 expression is the cause or the consequence. In addition, genderseparated analysis would be preferable.

\section{Aquaporin 9}

\section{Structure and permeability profile}

The $A Q P 9$ gene was first cloned from human liver cDNA and was found to encode a protein of 295 amino acids and, in contrast to AQP7, it contains the two highly conserved NPA motifs. It has a predicted molecular mass of $31.4 \mathrm{kDa}$ (Ishibashi et al. 1998). The AQP9 protein homology is $76 \%$ between human and mouse, $75 \%$ between human and rat

Published by Bioscientifica Ltd. 
(Ko et al. 1999), and 90\% between rat and mouse. Hydropathy analysis of human AQP9 predicts the characteristic six transmembrane domains with $\mathrm{N}$ - and C-terminal localized in the cytosol. A potential $N$-linked glycosylation site has been identified in the second extracellular loop at Asn-142 (Viadiu et al. 2007), and potential PKC and casein kinase II phosphorylation sites have been identified at the N-terminus (Ishibashi et al. 1998). The projection map at $7 \AA$ resolution of twodimensional AQP9 crystals indicates a tetrameric structure similar to other AQPs and that the pore size resembles the pore in GlpF (Viadiu et al. 2007). Immunoblotting for rat AQP9 protein results in a predominant band with a molecular size between $28 \mathrm{kDa}$ (Elkjaer et al. 2000) to $33 \mathrm{kDa}$ (Nihei et al. 2001), and additional bands at higher molecular weights that might represent glycosylated AQP9 products or oligomers (Elkjaer et al. 2000, Rodriguez et al. 2011). None of the additional bands were removed by deglycosylation with endoglycosidases (Nicchia et al. 2001); however, incubation with $N$-glycosidase $\mathrm{F}$ eliminated a $\sim 35 \mathrm{kDa}$ band (Viadiu et al. 2007), which is in agreement with the proposed $N$-linked glycosylation site in the second extracellular loop. In heterologous expression systems, AQP9 enhances the permeation of water and a wide range of small solutes, including polyols (glycerol, mannitol, and sorbitol), carbamids (urea and thiourea), monocarboxylates, purines (adenine), and pyrimidines (urasil and 5-FU) (Tsukaguchi et al. 1998, 1999, Carbrey et al. 2003, Jelen et al. 2011). Interestingly, AQP9 is also permeable to arsenite $\left(\mathrm{As}(\mathrm{OH})_{3}\right)$ (Liu et al. 2002, Carbrey et al. 2009), and one report also shows that AQP9 supports significant fluxes of $\mathrm{NH}_{3}$ and $\mathrm{NH}_{4}^{+}$ (Holm et al. 2005).

\section{Localization of AQP9 in the liver}

The localization of AQP9 has been investigated in humans as well as in rats and mice. The results are not fully unambiguous and some discrepancies between the various rodent and human expression sites exist (reviewed in Rojek et al. (2008)). In the liver, however, AQP9 protein demonstrates a similar localization in humans and rodents (Elkjaer et al. 2000, Rojek et al. 2007, Lebeck et al. 2012a). Here, AQP9 is localized to the plasma membrane domain of the hepatocytes, with the strongest labeling observed in the basolateral membrane domain facing the spaces of Disse (Nihei et al. 2001). Especially in females, AQP9 demonstrates a heterogeneous expression pattern within the liver. Thus, labeling for AQP9 is most abundant in the perivenous hepatocytes and gradually declines toward the portal triad. The gender-specific expression of AQP9 is also illustrated by female rats having 20\% lower AQP9 protein levels compared with males in the fed state (Nicchia et al. 2001).

\section{Is AQP9 the sole aquaglyceroporin in the liver?}

The presence of other aquaglyceroporins than AQP9 in the liver has been investigated with variable outcomes. Expression of AQP3 has been reported in murine liver (Patsouris et al. 2004). Contrasting results were, however, obtained in another study that was unable to detect either AQP3 or AQP7 expression at this site (Calamita et al. 2012). In the latter study, the authors also showed that the AQP inhibitor phloretin did not further reduce the glycerol permeability of the hepatocyte basolateral plasma membrane from AQP9 KO mice. This shows that AQP9 is the sole aquaglyceroporin contributing to the uptake of glycerol in murine liver. In human liver, the expression of both AQP3 and AQP7 protein has been reported (Rodriguez et al. 2011). Future studies are needed to clarify whether these aquaglyceroporins functionally overlap with AQP9 in human liver.

\section{Regulation of AQP9 expression in the liver}

Thus far, the regulation of hepatic AQP9 expression has only been observed at the transcriptional level. In male rodents, the hepatic expression of AQP9 is like AQP7 in adipose tissue inversely regulated by insulin. Thus, the hepatic AQP9 abundance is increased in response to fasting and decreased during refeeding (Kuriyama et al. 2002, Carbrey et al. 2003, Calamita et al. 2012), and STZ-induced diabetes mellitus results in an increased expression of AQP9 in the liver (Kuriyama et al. 2002, Carbrey et al. 2003). In accordance with the inverse relationship between insulin and hepatic AQP9 expression, a putative IRE ( -502 to $496 \mathrm{bp}$ ) has been identified in the promoter region of AQP9 (Kuriyama et al. 2002; Fig. 3). This IRE is similar to the one found in the promoter of phosphoenolpyruvate carboxykinase (PEPCK), a key enzyme in the gluconeogenic pathway. Insulin inhibits PEPCK gene transcription by inducing the phosphorylation of protein kinase B/Akt through the PI3K pathway. Akt then phosphorylates forkhead transcription factor 1 (FoxO1) and thereby causes its nuclear export and, thus, inhibits its binding to the IRE in the PEPCK promoter (Taniguchi et al. 2006). Whether the effect of insulin on AQP9 gene transcription is regulated by this pathway remains to be experimentally confirmed.

Published by Bioscientifica Ltd. 


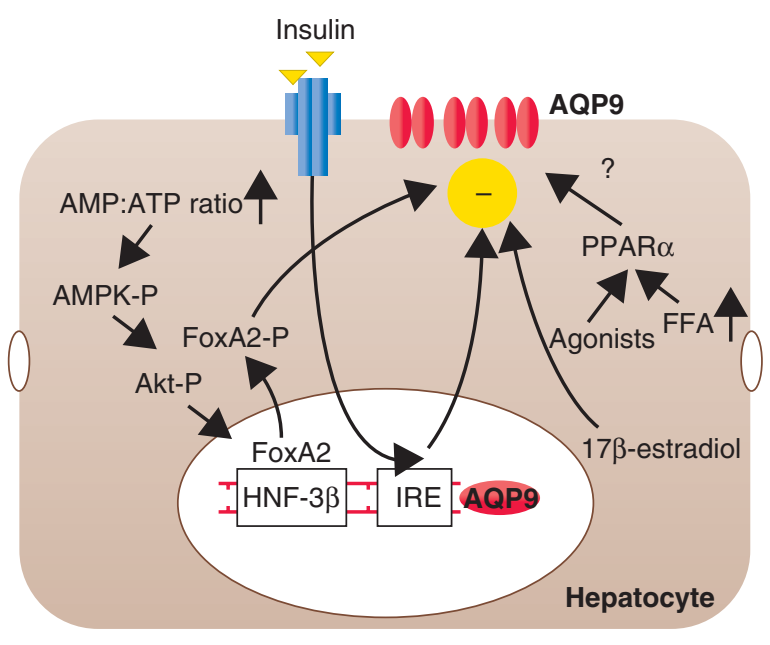

Figure 3

Signaling pathways reported thus far to be involved in regulating the hepatic expression of AQP9. In male rats, insulin inversely regulates the hepatic expression of AQP9 through an insulin response element (IRE) in the promoter region of the $A Q P 9$ gene. In male rats, this results in an increased hepatic expression of AQP9 during states of low insulin levels, whereas in females $17 \beta$-estradiol inhibits this increase supposedly by interfering with other signaling pathways. Activation of AMPK by phosphorylation (AMPK-P) also reduces the transcription of AQP9 by phosphorylating protein kinase B/Akt (Akt-P), which then phosphorylates the forkhead transcription factor, forkhead box A2 (FoxA2)/(HNF-3 $\beta$ ). This causes the nuclear extrusion of FoxA2 and thereby reduces its binding to the promoter region of AQP9. Under physiological conditions, AMPK activation occurs in response to increase in intracellular AMP:ATP ratios, such as seen during exercise and fasting. Finally, the peroxisome proliferator-activated receptor $\alpha$ (PPAR $\alpha$ ) is reported to be central for the increased expression of AQP9 in fasted male mice. Activation of PPAR $\alpha$ is stimulated by increased cytosolic levels of FFA and by agonists such as fibrates used in the treatment of hypertriglyceridemia.

An important point regarding the inverse regulation of AQP9 by insulin is that it only occurs in male rodents. We recently reported that the increased expression of hepatic AQP9 in response to fasting and STZ-induced diabetes mellitus does not occur in female rats (Lebeck et al. 2012b). The lack of increase in hepatic AQP9 was paralleled by a lower glycerol permeability of the basolateral plasma membrane of hepatocytes and accumulation of glycerol in the blood in fasted females. Ovariectomy resulted in an increase in the hepatic abundance of AQP9 in fasted females similar to that observed in males, whereas ovariectomy did not influence the hepatic abundance of AQP9 in the fed state. This, together with results obtained by in vitro studies in hepatocytes, suggests that $17 \beta$-estradiol $\left(\mathrm{E}_{2}\right)$ prevents the increase in hepatic AQP9 abundance by influencing signaling pathways that are activated during metabolic stress (Lebeck et al. 2012b). In support for $\mathrm{E}_{2}$ being involved in controlling hepatic AQP9 abundance, a separate study found that neonatal exposure to diethylstilbestrol was associated with lower hepatic AQP9 abundance in 20-day-old male rats (Wellejus et al. 2008).

Recently, an in vitro study in HepG2 cells showed that another forkhead transcription factor, forkhead box A2 (FoxA2 or HNF-3 $\beta$ ), could be involved in regulating hepatic AQP9 expression (Yokoyama et al. 2011). As illustrated in Fig. 3, a decreased transcription of the $A Q P 9$ gene was found in response to activation of AMPactivated protein kinase (AMPK), which increased the phosphorylation of Akt and thus the phosphorylation and nuclear extrusion of FoxA2 (Yokoyama et al. 2011). Several putative HNF-3 $\beta$ binding sites have been found in the promoter region of mouse AQP9 (Kuriyama et al. 2002), and the one affected by AMPK activation was reported to be between -1480 and $-278 \mathrm{bp}$ in the promoter of human AQP9 (Yokoyama et al. 2011). The physiological activator of AMPK is an increased AMP:ATP ratio such as seen during exercise and starvation and AMPK is known to promote energy generating pathways, whereas gluconeogenesis and lipogenesis are inhibited (Viollet et al. 2009). The nuclear extrusion of FoxA2 is also promoted by insulin, whereas during fasting and low insulin levels, FoxA2 increases the transcriptional programme of lipid oxidation and ketogenesis (Wolfrum et al. 2004). Hence, according to the in vitro studies on AMPK and AQP9, activation of AMPK during starvation in males would oppose the effects of the concurrent low insulin levels on AQP9 transcription. To this, it should, however, be noted that not all studies show increased activation of AMPK in response to fasting (Viollet et al. 2009).

PPAR $\alpha$ has also been linked to regulation of hepatic AQP9 abundance (Fig. 3). In the liver, PPAR $\alpha$ activation promotes fatty acid oxidation and ketogenesis and has also been linked to regulation of glucose metabolism (Kersten et al. 1999). In fasted WT male mice, increased levels of Ppar (Ppara) mRNA were paralleled by increased mRNA expression of $A q p 9, G l y K$, and Gpd1. This increase was abolished in male PPAR $\alpha$ KO mice, suggesting that PPAR $\alpha$ is central for the induction of AQP9 during starvation (Patsouris et al. 2004). In support, activation of PPAR $\alpha$ using the agonist WY 14643 also increased the expression of AQP9 protein in HepG2 cells (Lee et al. 2005). However, in female mice, WY 14643 treatment failed to affect the expression of hepatic AQP9 (Patsouris et al. 2004). As no PPRE has been reported in the AQP9 promoter, it could be speculated that the effect of PPAR $\alpha$ on hepatic AQP9 transcription is exerted through interfering with other transcription factor pathways. More studies are needed to elucidate the role of PPAR $\alpha$

Published by Bioscientifica Ltd. 
in the regulation of hepatic AQP9 expression. Finally, a single injection of glucagon in rats had no effect on the expression of AQP9 (Carbrey et al. 2003).

\section{Role of AQP9 in the liver: insights from AQP9 KO mice}

As outlined in Fig. 1, the glycerol released from adipose tissue through AQP7 during fasting reaches the liver where AQP9 facilitates its uptake. In the liver, the glycerol permeation step has been proposed to be rate-limiting for glycerol utilization within the hepatocyte (Li \& Lin 1983). As mentioned earlier, a recent study demonstrated that AQP9 serves as the only glycerol channel in mouse liver and that changes in AQP9 abundance are paralleled by alterations in the glycerol permeability of the basolateral plasma membrane (Calamita et al. 2012). The significance of AQP9 in facilitating uptake of glycerol was reported to be limited to the fasted state, whereas in the fed state the glycerol permeability of the hepatocyte basolateral plasma membrane was similar in WT and AQP9 KO mice (Calamita et al. 2012). However, AQP9 KO mice demonstrate increased p-glycerol levels in both the fed and fasted state compared with WT mice (Rojek et al. 2007), thus indicating that also in the fed state, AQP9 plays a significant role in the hepatic uptake of glycerol.

Once inside the hepatocyte, glycerol can be utilized for lipogenesis, gluconeogenesis, and glycolysis (Fig. 1). AQP9 has mainly been considered in a role of supplying glycerol for gluconeogenesis, due to the increased expression during states of low insulin levels in male rodents (Maeda et al. 2008, 2009). Even though AQP9 KO mice do not suffer from hypoglycemia in response to fasting, AQP9-deficient $L e p r^{d b} / L_{e p r^{d b}}$ mice that become obese and develop T2D have lower blood glucose levels than $L e p r^{d b} / L_{e p r}{ }^{d b}$ mice, suggesting that the obese AQP9 KO mice have a reduced capacity to generate glucose (Rojek et al. 2007). Furthermore, in obese insulin-resistant $\mathrm{db}+/ \mathrm{db}+$ mice, a 1.3-fold increase in hepatic AQP9 mRNA expression was paralleled by a higher hepatic glucose production from glycerol compared with lean control mice (Kuriyama et al. 2002). Finally, in contrast to WT mice, AQP9 KO mice do not increase the hepatic glucose output in response to perfusion with glycerol. Similar results were obtained in WT liver after treatment with an AQP9 inhibitor (Jelen et al. 2011). This shows that AQP9 plays a pivotal role in supplying glycerol for gluconeogenesis.

When considering the role of AQP9 in supplying glycerol for the different metabolic pathways, the distribution pattern of AQP9 within the liver should be taken into account. As outlined above, the expression of AQP9 is highest in the area surrounding the central vein with a gradual decline towards the portal triad. By contrast, according to the hepatic zonulation model, the expression of gluconeogenic enzymes is most abundant in the periportal hepatocytes with a gradual decline towards the central vein (Jungermann \& Katz 1989, Krones et al. 1998, Postic \& Girard 2008). Even though this, of course, gives a certain expression overlap, the physiological logic is not obvious. On the contrary, the hepatic zonulation model predicts relevance for AQP9 in supplying glycerol for glycolysis or TG synthesis.

As outlined above, a substantial part of the FFA that reaches the liver during fasting is re-esterified and either used for VLDL synthesis or stored in lipid droplets within the hepatocytes. The effect of AQP9 on hepatic TG generation remains largely unknown. Both fed and fasted AQP9 KO mice have higher plasma TG levels compared with AQP9 heterozygotes (Rojek et al. 2007), suggesting that AQP9 KO mice do not have a reduced capacity for generating TG. It should, however, be noted that plasma TG levels are often measured indirectly by detecting glycerol after hydrolysis of TG into glycerol and FFA, and therefore hyperglycerolemia can result in pseudohypertriglyceridemia. Two recent studies have linked AQP9 to hepatic TG accumulation and non-alcoholic fatty liver disease (NAFLD; Cai et al. 2013, Wang et al. 2013). Knockdown of AQP9 was reported to reduce the accumulation of TG in hepatocytes in both a rat and a cell culture model for NAFLD (Cai et al. 2013, Wang et al. 2013), thus suggesting a role for AQP9 in controlling hepatic TG synthesis.

Even though most studies have focused on the involvement of AQP9 in glycerol metabolism, the broad permeability profile of AQP9 suggests additional roles. As AQP9 is permeable to urea and as ureagenesis is increased in the catabolic states of fasting and diabetes, AQP9 could be hypothesized to play a role in facilitating the export of urea from the hepatocytes during these states. In support for this notion, the urea permeability of hepatocyte basolateral plasma membranes is reduced by $30 \%$ in AQP9 KO mice compared with WT mice. However, the AQP9 KO mice responded in a manner similar to WT mice when fed a high-protein diet, which increases the hepatic synthesis of urea, thus suggesting redundancy of AQP9 as a facilitator of urea transport (Jelen et al. 2012). This is also in agreement with the hepatic expression of AQP9 remaining unaffected by high-protein diets (Nicchia et al. 2001, Carbrey et al. 2003). Others have suggested a role for AQP9 in the hepatocellular hydration state and

Published by Bioscientifica Ltd. 
through this involvement in bile formation (Calamita et al. 2008). Finally, studies on AQP9 KO mice have also shown that AQP9 plays a role in hepatic arsenite excretion and thus provides partial protection of the whole animal from arsenic toxicity (Carbrey et al. 2009).

\section{Human studies on AQP9 expressed in liver}

Thus far, only a few studies have examined hepatic AQP9 in humans. The relative expression of AQP9 in the liver has been investigated in obese individuals with T2D and obese with no impairment of their glucose tolerance. This has given variable results with some reporting a reduced expression of AQP9 in T2D (Catalan et al. 2008, Rodriguez et al. 2011) and others finding no significant changes (Miranda et al. 2009). These findings contrast the increased expression of AQP9 found in male rodent models of diabetes (Kuriyama et al. 2002, Carbrey et al. 2003). Some of the human studies were performed in a mixed-gender cohort (Miranda et al. 2009, Rodriguez et al. 2011), which could affect the summarized outcome on hepatic AQP9 expression, if the gender-specific regulation of AQP9 in response to metabolic stress also applies to humans. On the other hand, studies on a human hepatocyte cell line (HepG2) showed an increased expression of AQP9 in response to insulin treatment, whereas leptin reduced the abundance of AQP9 (Rodriguez et al. 2011). This clearly contrasts the observations made in male rodents (Kuriyama et al. 2002, Carbrey et al. 2003), and even though the number of observations made in humans are still sparse, these results call for future studies to investigate whether the knowledge obtained for hepatic AQP9 in rodents has human relevance.

\section{Conclusion and perspectives}

Accumulating evidence suggest that AQP7 in adipose tissue and AQP9 in liver are glycerol channels with significant influence on glycerol metabolism within the two tissues. Even though not supported by all studies, results on mice and humans point towards a connection between low expression levels of AQP7 in adipose tissue and increased risk for development of obesity. Intriguingly, in humans, this association is found only in women. From a clinical point of view, a selective enhancement of AQP7 would seem like an interesting therapeutic target for treatment of obese women. However, before taking this step, the contribution of AQP7 expressed in other tissues to the metabolic phenotype needs further clarification.
In the liver, blocking of AQP9 could, at least in males, be a means to lower hepatic glucose production, especially in obese T2D, where glycerol availability and glycerol gluconeogenesis are increased. In addition, the novel association between AQP9 and NAFLD also suggests a beneficial effect of a reduced hepatic uptake of glycerol on hepatic TG accumulation. To clarify the potential for AQP9 as a pharmacological target, further studies on sexual dimorphism in hepatic glycerol metabolism and the role of AQP9 in TG synthesis seems to be of high importance. Finally, studies on whether results for AQP9 obtained in rodent models are of human relevance are of high priority.

\section{Declaration of interest}

The authors declare that there is no conflict of interest that could be perceived as prejudicing the impartiality of the review.

\section{Funding}

This work was supported by the Danish Diabetes Academy. The Academy is financed by a grant from the Novo Nordisk Foundation and co-financed by the Juvenile Diabetes Research Foundation (JDRF).

\section{Acknowledgements}

The author wishes to thank Jeppe Praetorius for his helpful constructive criticism of this review.

\section{References}

Baba H, Zhang XJ \& Wolfe RR 1995 Glycerol gluconeogenesis in fasting humans. Nutrition 11 149-153.

Best L, Brown PD, Yates AP, Perret J, Virreira M, Beauwens R, Malaisse WJ, Sener A \& Delporte C 2009 Contrasting effects of glycerol and urea transport on rat pancreatic $\beta$-cell function. Cellular Physiology and Biochemistry 23 255-264. (doi:10.1159/000218172)

Bortz WM, Paul P, Haff AC \& Holmes WL 1972 Glycerol turnover and oxidation in man. Journal of Clinical Investigation 51 1537-1546. (doi:10.1172/JCI106950)

Cai C, Wang C, Ji W, Liu B, Kang Y, Hu Z \& Jiang Z 2013 Knockdown of hepatic aquaglyceroporin-9 alleviates high fat diet-induced nonalcoholic fatty liver disease in rats. International Immunopharmacology 15 550-556. (doi:10.1016/j.intimp.2013.01.020)

Calamita G, Ferri D, Gena P, Carreras FI, Liquori GE, Portincasa P, Marinelli RA \& Svelto M 2008 Altered expression and distribution of aquaporin-9 in the liver of rat with obstructive extrahepatic cholestasis. American Journal of Physiology. Gastrointestinal and Liver Physiology 295 G682-G690. (doi:10.1152/ajpgi.90226.2008)

Calamita G, Gena P, Ferri D, Rosito A, Rojek A, Nielsen S, Marinelli RA, Fruhbeck G \& Svelto M 2012 Biophysical assessment of aquaporin-9 as principal facilitative pathway in mouse liver import of glucogenetic glycerol. Biology of the Cell 104 342-351. (doi:10.1111/boc.201100061)

Carbrey JM, Gorelick-Feldman DA, Kozono D, Praetorius J, Nielsen S \& Agre P 2003 Aquaglyceroporin AQP9: solute permeation and metabolic control of expression in liver. PNAS 100 2945-2950. (doi:10.1073/pnas. 0437994100) http://jme.endocrinology-journals.org DOI: 10.1530/JME-13-0268
C) 2014 Society for Endocrinology Printed in Great Britain 
Carbrey JM, Song L, Zhou Y, Yoshinaga M, Rojek A, Wang Y, Liu Y, Lujan HL, DiCarlo SE, Nielsen S et al. 2009 Reduced arsenic clearance and increased toxicity in aquaglyceroporin-9-null mice. PNAS 106 15956-15960. (doi:10.1073/pnas.0908108106)

Catalan V, Gomez-Ambrosi J, Pastor C, Rotellar F, Silva C, Rodriguez A, Gil MJ, Cienfuegos JA, Salvador J, Vendrell J et al. 2008 Influence of morbid obesity and insulin resistance on gene expression levels of AQP7 in visceral adipose tissue and AQP9 in liver. Obesity Surgery 18 695-701. (doi:10.1007/s11695-008-9453-7)

Ceperuelo-Mallafre V, Miranda M, Chacon MR, Vilarrasa N, Megia A, Gutierrez C, Fernandez-Real JM, Gomez JM, Caubet E, Fruhbeck G et al. 2007 Adipose tissue expression of the glycerol channel aquaporin-7 gene is altered in severe obesity but not in type 2 diabetes. Journal of Clinical Endocrinology and Metabolism 92 3640-3645. (doi:10.1210/ jc.2007-0531)

Clore JN, Glickman PS, Helm ST, Nestler JE \& Blackard WG 1989 Accelerated decline in hepatic glucose production during fasting in normal women compared with men. Metabolism 38 1103-1107. (doi:10.1016/0026-0495(89)90047-4)

Davis SN, Galassetti P, Wasserman DH \& Tate D 2000 Effects of gender on neuroendocrine and metabolic counterregulatory responses to exercise in normal man. Journal of Clinical Endocrinology and Metabolism 85 224-230. (doi:10.1210/jcem.85.1.6328)

El Hadri K, Feve B \& Pairault J 1996 Developmental expression and functional activity of $\beta 1$ - and $\beta 3$-adrenoceptors in murine 3T3-F442A differentiating adipocytes. European Journal of Pharmacology 297 107-119. (doi:10.1016/0014-2999(95)00723-7)

Elkjaer M, Vajda Z, Nejsum LN, Kwon T, Jensen UB, Amiry-Moghaddam M, Frokiaer J \& Nielsen S 2000 Immunolocalization of AQP9 in liver, epididymis, testis, spleen, and brain. Biochemical and Biophysical Research Communications 276 1118-1128. (doi:10.1006/bbrc.2000.3505)

Engel A, Fujiyoshi Y \& Agre P 2000 The importance of aquaporin water channel protein structures. EMBO Journal 19 800-806. (doi:10.1093/ emboj/19.5.800)

Fasshauer M, Klein J, Lossner U, Klier M, Kralisch S \& Paschke R 2003 Suppression of aquaporin adipose gene expression by isoproterenol, $\mathrm{TNF} \alpha$, and dexamethasone. Hormone and Metabolic Research 35 222-227. (doi:10.1055/s-2003-39075)

Fruhbeck G 2005 Obesity: aquaporin enters the picture. Nature $\mathbf{4 3 8}$ 436-437. (doi:10.1038/438436b)

Fruhbeck G, Catalan V, Gomez-Ambrosi J \& Rodriguez A 2006 Aquaporin-7 and glycerol permeability as novel obesity drug-target pathways. Trends in Pharmacological Sciences 27 345-347. (doi:10.1016/j.tips.2006.05.002)

Galassetti P, Tate D, Neill RA, Morrey S \& Davis SN 2002 Effect of gender on counterregulatory responses to euglycemic exercise in type 1 diabetes. Journal of Clinical Endocrinology and Metabolism 87 5144-5150. (doi:10.1210/jc.2002-020757)

Goubau C, Jaeken J, Levtchenko EN, Thys C, Di Michele M, Martens GA, Gerlo E, De Vos R, Buyse GM, Goemans N et al. 2013 Homozygosity for aquaporin $7 \mathrm{G} 264 \mathrm{~V}$ in three unrelated children with hyperglyceroluria and a mild platelet secretion defect. Genetics in Medicine 15 55-63. (doi:10.1038/gim.2012.90)

Guan HP, Li Y, Jensen MV, Newgard CB, Steppan CM \& Lazar MA 2002 A futile metabolic cycle activated in adipocytes by antidiabetic agents. Nature Medicine 8 1122-1128. (doi:10.1038/nm780)

Hales CN, Walker JB, Garland PB \& Randle PJ 1965 Fasting plasma concentrations of insulin, non-esterified fatty acids, glycerol and glucose in the early detection of diabetes mellitus. Lancet 1 65-67. (doi:10.1016/S0140-6736(65)91652-1)

Hammond VA \& Johnston DG 1987 Substrate cycling between triglyceride and fatty acid in human adipocytes. Metabolism 36 308-313. (doi:10.1016/0026-0495(87)90199-5)

Hanson RW \& Reshef L 2003 Glyceroneogenesis revisited. Biochimie 85 1199-1205. (doi:10.1016/j.biochi.2003.10.022)

Hara-Chikuma M, Sohara E, Rai T, Ikawa M, Okabe M, Sasaki S, Uchida S \& Verkman AS 2005 Progressive adipocyte hypertrophy in aquaporin- 7-deficient mice: adipocyte glycerol permeability as a novel regulator of fat accumulation. Journal of Biological Chemistry 280 15493-15496. (doi:10.1074/jbc.C500028200)

Hellerstein MK, Neese RA \& Schwarz JM 1993 Model for measuring absolute rates of hepatic de novo lipogenesis and reesterification of free fatty acids. American Journal of Physiology. Endocrinology and Metabolism 265 E814-E820.

Hibuse T, Maeda N, Funahashi T, Yamamoto K, Nagasawa A, Mizunoya W, Kishida K, Inoue K, Kuriyama H, Nakamura T et al. 2005 Aquaporin 7 deficiency is associated with development of obesity through activation of adipose glycerol kinase. PNAS 102 10993-10998. (doi:10.1073/pnas.0503291102)

Hibuse T, Maeda N, Nakatsuji H, Tochino Y, Fujita K, Kihara S, Funahashi T \& Shimomura I 2009 The heart requires glycerol as an energy substrate through aquaporin 7, a glycerol facilitator. Cardiovascular Research $\mathbf{8 3}$ 34-41. (doi:10.1093/cvr/cvp095)

Holm LM, Jahn TP, Moller AL, Schjoerring JK, Ferri D, Klaerke DA \& Zeuthen $\mathrm{T} 2005 \mathrm{NH} 3$ and $\mathrm{NH}_{4}{ }^{+}$permeability in aquaporin-expressing Xenopus oocytes. Pflügers Archiv: European Journal of Physiology $\mathbf{4 5 0}$ 415-428. (doi:10.1007/s00424-005-1399-1)

Ishibashi K, Kuwahara M, Gu Y, Kageyama Y, Tohsaka A, Suzuki F, Marumo F \& Sasaki S 1997 Cloning and functional expression of a new water channel abundantly expressed in the testis permeable to water, glycerol, and urea. Journal of Biological Chemistry 272 20782-20786. (doi:10.1074/ jbc.272.33.20782)

Ishibashi K, Kuwahara M, Gu Y, Tanaka Y, Marumo F \& Sasaki S 1998 Cloning and functional expression of a new aquaporin (AQP9) abundantly expressed in the peripheral leukocytes permeable to water and urea, but not to glycerol. Biochemical and Biophysical Research Communications 244 268-274.

Ishibashi K, Imai M \& Sasaki S 2000 Cellular localization of aquaporin 7 in the rat kidney. Experimental Nephrology 8 252-257. (doi:10.1006/ bbrc.1998.8252)

Jelen S, Wacker S, Aponte-Santamaria C, Skott M, Rojek A, Johanson U, Kjellbom P, Nielsen S, de Groot BL \& Rutzler M 2011 Aquaporin-9 protein is the primary route of hepatocyte glycerol uptake for glycerol gluconeogenesis in mice. Journal of Biological Chemistry $\mathbf{2 8 6}$ 44319-44325. (doi:10.1074/jbc.M111.297002)

Jelen S, Gena P, Lebeck J, Rojek A, Praetorius J, Frokiaer J, Fenton RA, Nielsen S, Calamita G \& Rutzler M 2012 Aquaporin-9 and urea transporter-A gene deletions affect urea transmembrane passage in murine hepatocytes. American Journal of Physiology. Gastrointestinal and Liver Physiology 303 G1279-G1287. (doi:10.1152/ajpgi.00153. 2012REF16=10.1055/s-2003-39075)

Jensen MD 2003 Fate of fatty acids at rest and during exercise: regulatory mechanisms. Acta Physiologica Scandinavica 178 385-390. (doi:10.1046/ j.1365-201X.2003.01167.x)

Jungermann K \& Katz N 1989 Functional specialization of different hepatocyte populations. Physiological Reviews 69 708-764.

Kahn BB \& Flier JS 2000 Obesity and insulin resistance. Journal of Clinical Investigation 106 473-481. (doi:10.1172/JCI10842)

Kersten S, Seydoux J, Peters JM, Gonzalez FJ, Desvergne B \& Wahli W 1999 Peroxisome proliferator-activated receptor $\alpha$ mediates the adaptive response to fasting. Journal of Clinical Investigation 103 1489-1498. (doi:10.1172/JCI6223REF22=10.1016/S0140-6736(65)91652-1)

Kishida K, Kuriyama H, Funahashi T, Shimomura I, Kihara S, Ouchi N, Nishida M, Nishizawa H, Matsuda M, Takahashi M et al. 2000 Aquaporin adipose, a putative glycerol channel in adipocytes. Journal of Biological Chemistry 275 20896-20902. (doi:10.1074/jbc.M001119200)

Kishida K, Shimomura I, Kondo H, Kuriyama H, Makino Y, Nishizawa H, Maeda N, Matsuda M, Ouchi N, Kihara S et al. 2001a Genomic structure and insulin-mediated repression of the aquaporin adipose (AQPap), adipose-specific glycerol channel. Journal of Biological Chemistry 276 36251-36260. (doi:10.1074/jbc.M106040200)

Kishida K, Shimomura I, Nishizawa H, Maeda N, Kuriyama H, Kondo H, Matsuda M, Nagaretani H, Ouchi N, Hotta K et al. 2001b Enhancement 
of the aquaporin adipose gene expression by a peroxisome proliferatoractivated receptor $\gamma$. Journal of Biological Chemistry 276 48572-48579. (doi:10.1074/jbc.M108213200)

Ko SB, Uchida S, Naruse S, Kuwahara M, Ishibashi K, Marumo F, Hayakawa T \& Sasaki S 1999 Cloning and functional expression of rAOP9L a new member of aquaporin family from rat liver. Biochemistry and Molecular Biology International 47 309-318.

Kolditz CI \& Langin D 2010 Adipose tissue lipolysis. Current Opinion in Clinical Nutrition and Metabolic Care 13 377-381. (doi:10.1097/MCO. 0b013e32833bed6a)

Kondo H, Shimomura I, Kishida K, Kuriyama H, Makino Y, Nishizawa H, Matsuda M, Maeda N, Nagaretani H, Kihara S et al. 2002 Human aquaporin adipose (AQPap) gene. Genomic structure, promoter analysis and functional mutation. European Journal of Biochemistry 269 1814-1826. (doi:10.1046/j.1432-1033.2002.02821.x)

Krones A, Kietzmann T \& Jungermann K 1998 Periportal localization of glucagon receptor mRNA in rat liver and regulation of its expression by glucose and oxygen in hepatocyte cultures. FEBS Letters 421 136-140. (doi:10.1016/S0014-5793(97)01556-1)

Kuriyama H, Kawamoto S, Ishida N, Ohno I, Mita S, Matsuzawa Y, Matsubara K \& Okubo K 1997 Molecular cloning and expression of a novel human aquaporin from adipose tissue with glycerol permeability. Biochemical and Biophysical Research Communications 241 53-58. (doi:10.1006/bbrc.1997.7769)

Kuriyama H, Shimomura I, Kishida K, Kondo H, Furuyama N, Nishizawa H, Maeda N, Matsuda M, Nagaretani H, Kihara S et al. 2002 Coordinated regulation of fat-specific and liver-specific glycerol channels, aquaporin adipose and aquaporin 9. Diabetes 51 2915-2921. (doi:10.2337/ diabetes.51REF33=10.1074/jbc.M111.297002)

Lafontan M \& Langin D 2009 Lipolysis and lipid mobilization in human adipose tissue. Progress in Lipid Research 48 275-297. (doi:10.1016/ j.plipres.2009.05.001)

Laforenza U, Gastaldi G, Grazioli M, Cova E, Tritto S, Faelli A, Calamita G \& Ventura U 2005 Expression and immunolocalization of aquaporin-7 in rat gastrointestinal tract. Biology of the Cell 97 605-613. (doi:10.1042/ BC20040090)

Laforenza U, Scaffino MF \& Gastaldi G 2013 Aquaporin-10 represents an alternative pathway for glycerol efflux from human adipocytes. PLoS ONE 8 e54474. (doi:10.1371/journal.pone.0054474)

Landau BR, Wahren J, Previs SF, Ekberg K, Chandramouli V \& Brunengraber H 1996 Glycerol production and utilization in humans: sites and quantitation. American Journal of Physiology. Endocrinology and Metabolism 271 E1110-E1117.

Lebeck J, Ostergard T, Rojek A, Fuchtbauer EM, Lund S, Nielsen S \& Praetorius J 2012a Gender-specific effect of physical training on AQP7 protein expression in human adipose tissue. Acta Diabetologica 49 215-226. (doi:10.1007/s00592-012-0430-1)

Lebeck J, Gena P, O'Neill H, Skowronski MT, Lund S, Calamita G \& Praetorius J $2012 b$ Estrogen prevents increased hepatic aquaporin-9 expression and glycerol uptake during starvation. American Journal of Physiology. Gastrointestinal and Liver Physiology 302 G365-G374. (doi:10.1152/ajpgi.00437.2011)

Lee DH, Park DB, Lee YK, An CS, Oh YS, Kang JS, Kang SH \& Chung MY 2005 The effects of thiazolidinedione treatment on the regulations of aquaglyceroporins and glycerol kinase in OLETF rats. Metabolism 54 1282-1289. (doi:10.1016/j.metabol.2005.04.015)

Lehrke M \& Lazar MA 2005 The many faces of PPAR $\gamma$. Cell 123 993-999. (doi:10.1016/j.cell.2005.11.026)

Leroyer SN, Tordjman J, Chauvet G, Quette J, Chapron C, Forest C \& Antoine B 2006 Rosiglitazone controls fatty acid cycling in human adipose tissue by means of glyceroneogenesis and glycerol phosphorylation. Journal of Biological Chemistry 281 13141-13149. (doi:10.1074/jbc.M512943200)

Li CC \& Lin EC 1983 Glycerol transport and phosphorylation by rat hepatocytes. Journal of Cellular Physiology 117 230-234. (doi:10.1002/ jcp.1041170214)
Lin EC 1977 Glycerol utilization and its regulation in mammals. Annual Review of Biochemistry 46 765-795. (doi:10.1146/annurev.bi.46.070177.004001)

Lindgren CM, Mahtani MM, Widen E, McCarthy MI, Daly MJ, Kirby A, Reeve MP, Kruglyak L, Parker A, Meyer J et al. 2002 Genomewide search for type 2 diabetes mellitus susceptibility loci in Finnish families: the Botnia study. American Journal of Human Genetics 70 509-516. (doi:10.1086/338629)

Liu Z, Shen J, Carbrey JM, Mukhopadhyay R, Agre P \& Rosen BP 2002 Arsenite transport by mammalian aquaglyceroporins AQP7 and AQP9. PNAS 99 6053-6058. (doi:10.1073/pnas.092131899)

Loos RJ, Katzmarzyk PT, Rao DC, Rice T, Leon AS, Skinner JS, Wilmore JH, Rankinen T \& Bouchard C 2003 Genome-wide linkage scan for the metabolic syndrome in the HERITAGE Family Study. Journal of Clinical Endocrinology and Metabolism 88 5935-5943. (doi:10.1210/ jc.2003-030553)

Luo TH, Zhao Y, Li G, Yuan WT, Zhao JJ, Chen JL, Huang W \& Luo M 2001 A genome-wide search for type II diabetes susceptibility genes in Chinese Hans. Diabetologia 44 501-506. (doi:10.1007/s001250051649)

Maeda N, Funahashi T, Hibuse T, Nagasawa A, Kishida K, Kuriyama H, Nakamura T, Kihara S, Shimomura I \& Matsuzawa Y 2004 Adaptation to fasting by glycerol transport through aquaporin 7 in adipose tissue. PNAS 101 17801-17806. (doi:10.1073/pnas.0406230101)

Maeda N, Funahashi T \& Shimomura I 2008 Metabolic impact of adipose and hepatic glycerol channels aquaporin 7 and aquaporin 9 . Nature Clinical Practice. Endocrinology \& Metabolism 4 627-634. (doi:10.1038/ncpendmet0980)

Maeda N, Hibuse T \& Funahashi T 2009 Role of aquaporin-7 and aquaporin-9 in glycerol metabolism; involvement in obesity. Handbook of Experimental Pharmacology 190 233-249. (doi:10.1007/978-3-54079885-9 12)

Magni F, Sarto C, Ticozzi D, Soldi M, Bosso N, Mocarelli P \& Kienle MG 2006 Proteomic knowledge of human aquaporins. Proteomics 6 5637-5649. (doi:10.1002/pmic.200600212)

Marrades MP, Milagro FI, Martinez JA \& Moreno-Aliaga MJ 2006 Differential expression of aquaporin 7 in adipose tissue of lean and obese high fat consumers. Biochemical and Biophysical Research Communications 339 785-789. (doi:10.1016/j.bbrc.2005.11.080)

Matsumura K, Chang BH, Fujimiya M, Chen W, Kulkarni RN, Eguchi Y, Kimura H, Kojima H \& Chan L 2007 Aquaporin 7 is a $\beta$-cell protein and regulator of intraislet glycerol content and glycerol kinase activity, $\beta$-cell mass, and insulin production and secretion. Molecular and Cellular Biology 27 6026-6037. (doi:10.1128/МСB.00384-07)

Miranda M, Ceperuelo-Mallafre V, Lecube A, Hernandez C, Chacon MR, Fort JM, Gallart L, Baena-Fustegueras JA, Simo R \& Vendrell J 2009 Gene expression of paired abdominal adipose AQP7 and liver AQP9 in patients with morbid obesity: relationship with glucose abnormalities. Metabolism 58 1762-1768. (doi:10.1016/j.metabol.2009.06.004)

Miranda M, Escote X, Ceperuelo-Mallafre V, Alcaide MJ, Simon I, Vilarrasa N, Wabitsch M \& Vendrell J 2010 Paired subcutaneous and visceral adipose tissue aquaporin-7 expression in human obesity and type 2 diabetes: differences and similarities between depots. Journal of Clinical Endocrinology and Metabolism 95 3470-3479. (doi:10.1210/ jc. 2009-2655)

Mittendorfer B, Horowitz JF \& Klein S 2001 Gender differences in lipid and glucose kinetics during short-term fasting. American Journal of Physiology. Endocrinology and Metabolism 281 E1333-E1339.

Mittendorfer B, Horowitz JF \& Klein S 2002 Effect of gender on lipid kinetics during endurance exercise of moderate intensity in untrained subjects. American Journal of Physiology. Endocrinology and Metabolism 283 E58-E65. (doi:10.1152/ajpendo.00504.2001)

Monjo M, Pujol E \& Roca P $2005 \alpha 2$ - to $\beta 3$-Adrenoceptor switch in 3T3-L1 preadipocytes and adipocytes: modulation by testosterone, $17 \beta$-estradiol, and progesterone. American Journal of Physiology. Endocrinology and Metabolism 289 E145-E150. (doi:10.1152/ajpendo.00563.2004)

Nejsum LN, Elkjaer M, Hager H, Frokiaer J, Kwon TH \& Nielsen S 2000 Localization of aquaporin-7 in rat and mouse kidney using RT-PCR, 
immunoblotting, and immunocytochemistry. Biochemical and Biophysical Research Communications 277 164-170. (doi:10.1006/bbrc. 2000.3638)

Nicchia GP, Frigeri A, Nico B, Ribatti D \& Svelto M 2001 Tissue distribution and membrane localization of aquaporin-9 water channel: evidence for sex-linked differences in liver. Journal of Histochemistry and Cytochemistry 49 1547-1556. (doi:10.1177/002215540104901208)

Nihei K, Koyama Y, Tani T, Yaoita E, Ohshiro K, Adhikary LP, Kurosaki I, Shirai Y, Hatakeyama K \& Yamamoto T 2001 Immunolocalization of aquaporin-9 in rat hepatocytes and Leydig cells. Archives of Histology and Cytology 64 81-88. (doi:10.1679/aohc.64.81)

Nurjhan N, Campbell PJ, Kennedy FP, Miles JM \& Gerich JE 1986 Insulin dose-response characteristics for suppression of glycerol release and conversion to glucose in humans. Diabetes 35 1326-1331. (doi:10.2337/diab.35.12.1326)

Pastor-Soler N, Bagnis C, Sabolic I, Tyszkowski R, McKee M, Van Hoek A, Breton S \& Brown D 2001 Aquaporin 9 expression along the male reproductive tract. Biology of Reproduction 65 384-393. (doi:10.1095/ biolreprod65.2.384)

Patsouris D, Mandard S, Voshol PJ, Escher P, Tan NS, Havekes LM, Koenig W, Marz W, Tafuri S, Wahli W et al. 2004 PPAR $\alpha$ governs glycerol metabolism. Journal of Clinical Investigation 114 94-103. (doi:10.1172/JCI200420468)

Peroni O, Large V, Diraison F \& Beylot M 1997 Glucose production and gluconeogenesis in postabsorptive and starved normal and streptozotocin-diabetic rats. Metabolism 46 1358-1363. (doi:10.1016/ S0026-0495(97)90244-4)

Postic C \& Girard J 2008 Contribution of de novo fatty acid synthesis to hepatic steatosis and insulin resistance: lessons from genetically engineered mice. Journal of Clinical Investigation 118 829-838. (doi:10.1172/JCI34275)

Prudente S, Flex E, Morini E, Turchi F, Capponi D, De Cosmo S, Tassi V, Guida V, Avogaro A, Folli F et al. 2007 A functional variant of the adipocyte glycerol channel aquaporin 7 gene is associated with obesity and related metabolic abnormalities. Diabetes 56 1468-1474. (doi:10.2337/db06-1389)

Reshef L, Olswang Y, Cassuto H, Blum B, Croniger CM, Kalhan SC, Tilghman SM \& Hanson RW 2003 Glyceroneogenesis and the triglyceride/fatty acid cycle. Journal of Biological Chemistry $\mathbf{2 7 8}$ 30413-30416. (doi:10.1074/jbc.R300017200)

Rodriguez A, Catalan V, Gomez-Ambrosi J, Garcia-Navarro S, Rotellar F, Valenti V, Silva C, Gil MJ, Salvador J, Burrell MA et al. 2011 Insulin- and leptin-mediated control of aquaglyceroporins in human adipocytes and hepatocytes is mediated via the PI3K/Akt/mTOR signaling cascade. Journal of Clinical Endocrinology and Metabolism 96 E586-E597. (doi:10.1210/jc.2010-1408)

Rojek AM, Skowronski MT, Fuchtbauer EM, Fuchtbauer AC, Fenton RA, Agre P, Frokiaer J \& Nielsen S 2007 Defective glycerol metabolism in aquaporin 9 (AQP9) knockout mice. PNAS 104 3609-3614. (doi:10.1073/pnas.0610894104)

Rojek A, Praetorius J, Frokiaer J, Nielsen S \& Fenton RA 2008 A current view of the mammalian aquaglyceroporins. Annual Review of Physiology $\mathbf{7 0}$ 301-327. (doi:10.1146/annurev.physiol.70.113006.100452)

Sjoholm K, Palming J, Olofsson LE, Gummesson A, Svensson PA, Lystig TC, Jennische E, Brandberg J, Torgerson JS, Carlsson B et al. 2005 A microarray search for genes predominantly expressed in human omental adipocytes: adipose tissue as a major production site of serum amyloid. Journal of Clinical Endocrinology and Metabolism 90 2233-2239. (doi:10.1210/jc.2004-1830)

Skowronski MT, Lebeck J, Rojek A, Praetorius J, Fuchtbauer EM, Frokiaer J \& Nielsen S 2007 AQP7 is localized in capillaries of adipose tissue, cardiac and striated muscle: implications in glycerol metabolism. American
Journal of Physiology. Renal Physiology 292 F956-F965. (doi:10REF100=10.1369/jhc.7A7366.2007)

Sohara E, Rai T, Miyazaki J, Verkman AS, Sasaki S \& Uchida S 2005 Defective water and glycerol transport in the proximal tubules of AQP7 knockout mice. American Journal of Physiology. Renal Physiology 289 F1195-F1200. (doi:10.1152/ajprenal.00133.2005)

Tan GD, Debard C, Tiraby C, Humphreys SM, Frayn KN, Langin D, Vidal H \& Karpe F 2003 A "futile cycle" induced by thiazolidinediones in human adipose tissue? Nature Medicine 9 811-812. (doi:10.1038/ nm0703-811)

Taniguchi CM, Emanuelli B \& Kahn CR 2006 Critical nodes in signalling pathways: insights into insulin action. Nature Reviews. Molecular Cell Biology 7 85-96. (doi:10.1038/nrm1837)

Tordjman J, Chauvet G, Quette J, Beale EG, Forest C \& Antoine B 2003 Thiazolidinediones block fatty acid release by inducing glyceroneogenesis in fat cells. Journal of Biological Chemistry 278 18785-18790. (doi:10.1074/jbc.M206999200)

Tsukaguchi H, Shayakul C, Berger UV, Mackenzie B, Devidas S, Guggino WB, van Hoek AN \& Hediger MA 1998 Molecular characterization of a broad selectivity neutral solute channel. Journal of Biological Chemistry $\mathbf{2 7 3}$ 24737-24743. (doi:10.1074/jbc.273.38.24737)

Tsukaguchi H, Weremowicz S, Morton CC \& Hediger MA 1999 Functional and molecular characterization of the human neutral solute channel aquaporin-9. American Journal of Physiology 277 F685-F696.

Viadiu H, Gonen T \& Walz T 2007 Projection map of aquaporin-9 at 7 A resolution. Journal of Molecular Biology 367 80-88. (doi:10.1016/j.jmb. 2006.12.042)

Viollet B, Guigas B, Leclerc J, Hebrard S, Lantier L, Mounier R, Andreelli F \& Foretz M 2009 AMP-activated protein kinase in the regulation of hepatic energy metabolism: from physiology to therapeutic perspectives. Acta Physiologica 196 81-98. (doi:10.1111/j.1748-1716.2009.01970.x)

Walker CG, Holness MJ, Gibbons GF \& Sugden MC 2007 Fasting-induced increases in aquaporin 7 and adipose triglyceride lipase mRNA expression in adipose tissue are attenuated by peroxisome proliferatoractivated receptor $\alpha$ deficiency. International Journal of Obesity $\mathbf{3 1}$ 1165-1171. (doi:10.1038/sj.ijo.0803555)

Wang C, Lv ZL, Kang YJ, Xiang TX, Wang PL \& Jiang Z 2013 Aquaporin-9 downregulation prevents steatosis in oleic acid-induced non-alcoholic fatty liver disease cell models. International Journal of Molecular Medicine 32 1159-1165. (doi:10.3892/ijmm.2013.1502)

Weissenborn DL, Wittekindt N \& Larson TJ 1992 Structure and regulation of the glpFK operon encoding glycerol diffusion facilitator and glycerol kinase of Escherichia coli K-12. Journal of Biological Chemistry 267 6122-6131.

Wellejus A, Jensen HE, Loft S \& Jonassen TE 2008 Expression of aquaporin 9 in rat liver and efferent ducts of the male reproductive system after neonatal diethylstilbestrol exposure. Journal of Histochemistry and Cytochemistry 56 425-432. (doi:10.1369/jhc.7A7366.2007)

Wolfe RR, Klein S, Carraro F \& Weber JM 1990 Role of triglyceride-fatty acid cycle in controlling fat metabolism in humans during and after exercise. American Journal of Physiology. Endocrinology and Metabolism 258 E382-E389.

Wolfrum C, Asilmaz E, Luca E, Friedman JM \& Stoffel M 2004 Foxa2 regulates lipid metabolism and ketogenesis in the liver during fasting and in diabetes. Nature $\mathbf{4 3 2}$ 1027-1032. (doi:10.1038/ nature03047)

Yki-Jarvinen H 2004 Thiazolidinediones. New England Journal of Medicine 351 1106-1118. (doi:10.1056/NEJMra041001)

Yokoyama Y, Iguchi K, Usui S \& Hirano K 2011 AMP-activated protein kinase modulates the gene expression of aquaporin 9 via forkhead box a2. Archives of Biochemistry and Biophysics 515 80-88. (doi:10.1016/ j.abb.2011.08.002)

Received in final form 18 January 2014

Accepted 23 January 2014

Accepted Preprint published online 24 January 2014 http://jme.endocrinology-journals.org DOI: 10.1530/JME-13-0268
() 2014 Society for Endocrinology Printed in Great Britain 